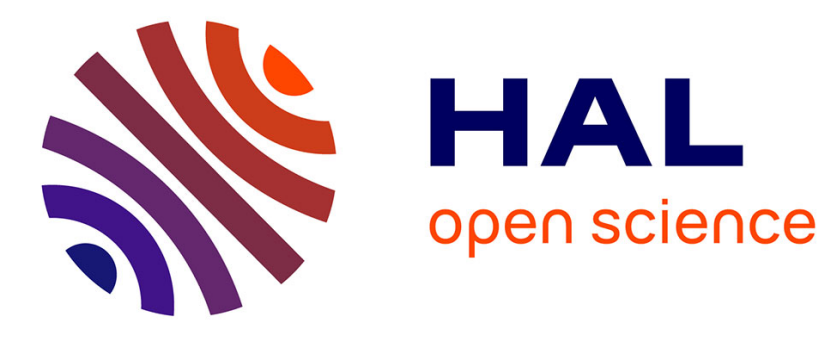

\title{
Age, weight and decompression sickness in rats
}

Peter Buzzacott, Michael Theron, Aleksandra Mazur, Qiong Wang, Kate

Lambrechts, Ingrid Eftedal, Simin Berenji Ardestani, François Guerrero

\section{To cite this version:}

Peter Buzzacott, Michael Theron, Aleksandra Mazur, Qiong Wang, Kate Lambrechts, et al.. Age, weight and decompression sickness in rats. Archives of Physiology and Biochemistry, 2016, 122 (2), pp.67 - 69. 10.3109/13813455.2016.1140787 . hal-01412101

\section{HAL Id: hal-01412101 \\ https://hal.univ-brest.fr/hal-01412101}

Submitted on 5 Mar 2018

HAL is a multi-disciplinary open access archive for the deposit and dissemination of scientific research documents, whether they are published or not. The documents may come from teaching and research institutions in France or abroad, or from public or private research centers.
L'archive ouverte pluridisciplinaire HAL, est destinée au dépôt et à la diffusion de documents scientifiques de niveau recherche, publiés ou non, émanant des établissements d'enseignement et de recherche français ou étrangers, des laboratoires publics ou privés. 


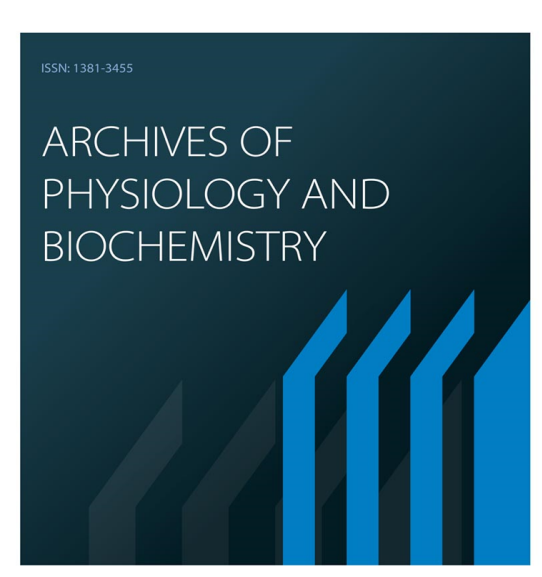

www.tandfonline.com/iarp

\title{
Age, weight and decompression sickness in rats
}

Peter Buzzacott, Michael Theron, Aleksandra Mazur, Qiong Wang, Kate Lambrechts, Ingrid Eftedal, Simin Berenji Ardestani, François Guerrero

Doi: $10.3109 / 13813455.2016 .1140787$

\begin{abstract}
Objective: The aim of this study was to determine if, after controlling for weight, age is associated with decompression sickness (DCS) in rats.

Methods: Following compression-decompression, male rats aged 11 weeks were observed for DCS. After two weeks recovery surviving rats were re-dived using the same compression-decompression profile.

Results: In this experiment there was a clear difference between DCS outcome at ages 11 or 13 weeks in matched rats $(p=0.002)$.

Discussion: Even with weight included in the model age was significantly associated with DCS $(p=0.01)$, yet after removal of weight the association was much stronger
\end{abstract}

$(p=0.002)$.

Conclusion: We believe that age is likely to be found associated with the probability of DCS in a larger dataset with a wider range of parameters, after accounting for the effect of weight.

(C) 2016 Taylor \& Francis. This provisional PDF corresponds to the article as it appeared upon acceptance. Fully formatted PDF and full text (HTML) versions will be made available soon.

DISCLAIMER: The ideas and opinions expressed in the journal's Just Accepted articles do not necessarily reflect those of Taylor \& Francis (the Publisher), the Editors or the journal. The Publisher does not assume any responsibility for any injury and/or damage to persons or property arising from or related to any use of the material contained in these articles. The reader is advised to check the appropriate medical literature and the product information currently provided by the manufacturer of each drug to be administered to verify the dosages, the method and duration of administration, and contraindications. It is the responsibility of the treating physician or other health care professional, relying on his or her independent experience and knowledge of the patient, to determine drug dosages and the best treatment for the patient. Just Accepted articles have undergone full scientific review but none of the additional editorial preparation, such as copyediting, typesetting, and proofreading, as have articles published in the traditional manner. There may, therefore, be errors in Just Accepted articles that will be corrected in the final print and final online version of the article. Any use of the Just Accepted articles is subject to the express understanding that the papers have not yet gone through the full quality control process prior to publication. 
Age, weight and decompression sickness in rats

by

Peter Buzzacott,* Michael Theron, Aleksandra Mazur, Qiong Wang, Kate Lambrechts, Ingrid Eftedal, Simin Berenji Ardestani, François Guerrero.

*Corresponding author

Keywords: Decompression illness, diving, Long-Evans, regression modelling.

Peter Buzzacott is a Marie Curie Experienced Research Fellow, Université de Bretagne Occidentale, Laboratoire Optimisation des Régulations Physiologiques (ORPhy), UFR Sciences et Techniques, 6 avenue Le Gorgeu, CS 93837, 29200 Brest Cedex 3, France, and an Adjunct Lecture at the School of Sports Science, Exercise and Health, the University of Western Australia, 35 Stirling Highway, Crawley, WA 6009, Australia.

Ph: +33 (2) 98016235

E-mail: peter.buzzacott@uwa.edu.au

Michael Theron, Director, Université de Bretagne Occidentale, Laboratoire Optimisation des Régulations Physiologiques (ORPhy), UFR Sciences et Techniques, 6 avenue Le Gorgeu, CS 93837, 29200 Brest Cedex 3, France. E-mail: Michael.theron@univ-brest.fr

Aleksandra Mazur, Research Fellow, Université de Bretagne Occidentale, Laboratoire Optimisation des Régulations Physiologiques (ORPhy), UFR Sciences et Techniques, 6 avenue Le Gorgeu, CS 93837, 29200 Brest Cedex 3, France. E-mail :

maz.aleksandra@gmail.com

Qiong Wang, Research Fellow, Université de Bretagne Occidentale, Laboratoire Optimisation des Régulations Physiologiques (ORPhy), UFR Sciences et Techniques, 6 avenue Le Gorgeu, CS 93837, 29200 Brest Cedex 3, France. E-mail : wangqiong0008204@yahoo.com

Kate Lambrechts, Research Fellow, Université de Bretagne Occidentale, Laboratoire Optimisation des Régulations Physiologiques (ORPhy), UFR Sciences et Techniques, 6 avenue Le Gorgeu, CS 93837, 29200 Brest Cedex 3, France. E-mail : lambrechtskate@hotmail.com

Ingrid Eftedal, Researcher, Norwegian University of Science and Technology, Department of Circulation and Medical Imaging, Postbox 8905, 7491 Trondheim, Norway. E-mail: ingrid.eftedal@ntnu.no

Simin Berenji Ardestani, Research assistant, Norwegian University of Science and Technology, Department of Circulation and Medical Imaging, Postbox 8905, 7491 Trondheim, Norway. E-mail: siminb@stud.ntnu.no

François Guerrero, Director, Université de Bretagne Occidentale, Laboratoire Optimisation des Régulations Physiologiques (ORPhy), UFR Sciences et Techniques, 6 avenue Le Gorgeu, CS 93837, 29200 Brest Cedex 3, France. E-mail : francois.guerrero@univ-brest.fr 
Age, weight and decompression sickness in rats

\section{Abstract}

Objective: The aim of this study was to determine if, after controlling for weight, age is associated with decompression sickness (DCS) in rats.

Methods: Following compression-decompression, male rats aged 11 weeks were observed for DCS. After two weeks recovery surviving rats were re-dived using the same compressiondecompression profile.

Results: In this experiment there was a clear difference between DCS outcome at ages 11 or 13 weeks in matched rats $(\mathrm{p}=0.002)$.

Discussion: Even with weight included in the model age was significantly associated with DCS $(\mathrm{p}=0.01)$, yet after removal of weight the association was much stronger $(\mathrm{p}=0.002)$.

Conclusion: We believe that age is likely to be found associated with the probability of DCS in a larger dataset with a wider range of parameters, after accounting for the effect of weight. 


\section{Introduction}

Age is a factor of interest for decompression sickness (DCS) research in diving humans (Carturan et al., 2002, Carturan et al., 1999). Both diving and aging exert distinct influences over cardiovascular function though the nature of their relationship when combined remains uncertain (Boussuges et al., 2009). With senescence the cardiovascular system undergoes complex structural and functional changes (Ardestani et al., 2015

). Diving too may lead to vascular dysfunction and endothelial cell death (Lambrechts et al., 2013, Wang et al., 2014).

Aging induces phenotypical changes in human coronary arterioles that are similar to the ageassociated remodeling of the walls of large arteries seen in rats, age is associated with increasing endothelial dysfunction in both humans and rodents (Lakatta, 2003) and agerelated endothelial dysfunction has been observed in coronary arterioles of approximately 80week old rats (Csiszar et al., 2002) corresponding to a human age of 90 years (Sengupta, 2013). Rats are also a useful model for researching DCS (Mazur et al., 2014), particularly as the majority of DCS research in humans is, by necessity, retrospective (Sulaiman et al., 1997). Since age-associated cardiovascular changes have been found comparable between humans and rats, we propose that rat model research might help elucidate the relationship between age and risk of DCS in humans. The number of data required for such an analysis is of the order of many hundreds therefore rat models offers a convenient alternative to studying DCS in humans. For rat research though, age is confounded by weight, which increases with age (Figure 1), and weight is a known risk factor for DCS in rats (Lillo and MacCallum, 1991, Arieli et al., 2007).

The aim of this study was to determine if age is associated with DCS outcome in rats after controlling for weight. The purpose of this study was support investment into a substantial 
modelling project to estimate the size of the effect of age upon DCS outcome in rats. If no correlation between age and DCS was observed in this study then the modelling endeavour to estimate the effect size of age upon DCS would not proceed.

\section{Methods}

Male Long-Evans rats $(n=20)$ were obtained in two batches, two weeks apart, from Janvier SAS (Le Genest St Isle, France) at age 10 weeks. Long Evans were included in this experiment for their wide variation in weight at 11 weeks and their rapid growth (a median increase of $20 \%$ bodyweight) over the following two weeks (median $58 \mathrm{~g}$, range $20-90 \mathrm{~g}$ ). The rats were housed for one week before the experiment in the Faculty of Sciences and Techniques vivarium in standard conditions, (mean temperature $21.2^{\circ} \mathrm{C}+/-0.2$, relative humidity $27 \%+/-16 \%, 12$ hour light:dark cycle, $7 \mathrm{am}-7 \mathrm{pm}$ ), during which they had access to water and rat chow ad libitum. Hydration was withdrawn 30 mins before compression. The rats were weighed on the day of diving before being compressed in a 170-litre hyperbaric chamber (Comex, Marseille, France). All dives commenced in the morning after 8am.

The air inside the chamber was compressed to $1000 \mathrm{kPa}$ at the rate of $100 \mathrm{kPa}$ per minute. Maximum pressure was held for 45-minutes followed by decompression at 100kPa per minute to $200 \mathrm{kPa}$. Decompression was thereafter staged with five mins at $200 \mathrm{kPa}$, five mins at $160 \mathrm{kPa}$ and $10 \mathrm{mins}$ at $130 \mathrm{kPa}$. This protocol has been shown to produce DCS signs in a predictable proportion of male rats aged 10-11 weeks (Buzzacott et al., 2014).

Following decompression the rats were swiftly removed from the chamber and observed for signs of DCS for one hour. DCS classification was No observable DCS (no-DCS)=0, respiratory distress or paralysis (survived-DCS $)=1$, or death within one hour $($ dead-DCS $)=2$. 
The diagnosis was noted by two observers in each case. The observation period ended at 60 minutes and mortality, morbidity or apparent health was noted.

After two weeks recovery the surviving rats were re-dived using the same compressiondecompression profile. In rats at this post-adolescent stage of their lives, two weeks equates to a little over one year of young adult development in humans. This research, including death as an endpoint, was approved by Universite de Bretagne Occidentale animal research ethic committee and the French Ministry of Agriculture (R-2011-FG-01). A pain-display scale was also approved by the ethic committee and any animal displaying signs at the predetermined threshold $(n=1)$ was immediately euthanized with an intraperitoneal injection of a lethal dose of sodium-pentobarbital. All rats showing signs of DCS below the threshold recovered within 30 mins and were indistinguishable from the other survivors at $60 \mathrm{mins}$, as has been previously reported (Lillo, 1988, Sallee and Adams, 1970).

\section{ANALYSIS}

Potential predictors of DCS outcome were analysed using SAS ver 9.3 (SAS, Cary, North Carolina). Significance of age was assessed using ordinal logistic regression with weight on the day of diving included in the model, (Eq. 1), since weight is known to have a significant effect upon likelihood of DCS (Mazur et al., 2014). The rats were compressed one or two at a time, in with other rats of different strains for other experiments to be reported elsewhere. Model fit of the dataset was optimised using the likelihood ratio test with one degree of freedom comparing the log likelihood (-2LL) of the full model (Eq. 1) with the diminished model, which is appropriate for small datasets when only one of two parameters is to be removed.

$$
\operatorname{Ln}\left(\frac{P_{j}}{1-P_{j}}\right)=\alpha_{j}+\beta_{1} \text { Age }+\beta_{2} \text { Weight }
$$


The modelled probability (P) of a ternary DCS outcome state $j$, (of no-DCS, survived-DCS or dead-DCS), is been described in detail elsewhere (Buzzacott et al., 2014). Briefly, the probability of no-DCS (vs. DCS) is calculated, then the probability of dead-DCS (vs. alive). The probability of survived-DCS is then determined by subtracting the probabilities of noDCS and dead-DCS from 1.0, which is the sum of all possible probabilities. Significance was accepted at $\mathrm{p}<0.05$ and we had $80 \%$ power to detect a difference of $\pm 30 \%$ DCS within 20 rats at the $\mathrm{p}<0.05$ level of significance.

Lastly, we predicted what theoretical effect the four rats who made only the first dive would have had if they had had the opportunity to live through the second dive, which would have moved the data towards the null hypothesis (that additional age had the opposite effect upon DCS outcome). 


\section{Results}

Mean weight by age and block is shown in Table 1 . The mean weight of Batch 1 at age 13 weeks effectively cancelled out the effect of weight in Batch 2 at age 11 weeks (Table 1, in bold). During the first dive one rat from each Batch died from DCS, one rat from Batch 1 was excluded from the second dive after the cage it was in was mislabelled and one rat from Batch 2 was euthanized after the first dive to alleviate pain. DCS outcome by age is shown in Figure 1.

The $-2 \mathrm{LL}$ of the initial model was 46.967 , the $-2 \mathrm{LL}=54.458$ after age was removed (difference=7.491) and the $-2 L L=47.439$ after weight was removed (difference=0.472). Removing weight did not significantly worsen the model $(\mathrm{p}>0.25)$ but removing age did $(p<0.01)$ therefore weight was removed from the model. Age was then shown to be significantly associated with the probability of suffering DCS $(\mathrm{p}=0.002)$. In this experiment there was a clear difference between DCS outcome at ages 11 or 13 weeks in matched rats. If the four rats excluded from the second dive had each hypothetically survived it then age would have remained significant $(\mathrm{p}=0.008)$. 


\section{Discussion}

Even with weight included in the model age was significantly associated with DCS $(\mathrm{p}=0.01)$, yet after removal of weight the association was much stronger $(\mathrm{p}=0.002)$, therefore we believe that age is likely to be found associated with the probability of DCS in a large dataset with a wider range of parameters, after accounting for the effect of weight. The estimated size of the effect of age we observed (Fig. 1) was considerably greater than we previously reported in Sprague-Dawley rats between the ages of 11 and 13 weeks and therefore we speculate that the effect size in a larger analysis with multiple strains might be substantially smaller (Mazur et al., 2014). Lillo et al (2002) suggest weight has an exponential effect upon risk of DCS but this study did not primarily aim to estimate effect size, rather the aim was confirm if a relationship exists between age and DCS after controlling for weight. Given that the mean weight in Batch 1 at 13 weeks was equivalent to the mean weight in Batch 2 at 11 weeks, weight was controlled for through study design and the effect size of weight not explored. Given the outcome had three ordinal levels, ordinal logistic regression was an appropriate method of model-fitting in this instance.

There are many limitations in a small test-retest experiment such as this, including that the effect of a second exposure (through matched controls) is a potential confounder. The second dive was made after two weeks recovery and all rats appeared healthy but we cannot exclude the possible influence of stress, either more or less, than during the first exposure. It is also possible that the rats' resistance deteriorated over an additional two weeks of housing in our vivarium, for example if they were subjected to low temperature or humidity, noise, etc, but we consider this unlikely because other rats were housed in the same vivarium over the same period and their health showed no signs of housing stress, not to mention that the rats in this experiment showed considerable weight gain over the two week rest period. Indeed, prior 
hyperbaric exposure has been shown to acclimate rats to compression/decompression, increasing their likelihood of survival (Montcalm-Smith et al., 2010).

Hormonal levels may have increased during the two week interlude but that might not confound the effect of age since hormonal levels are tied with age, especially when sexual maturity is first reached as in this study. Hormones were recently suggested as a potential explanation for the difference in DCS outcome between male and female rats (Mazur et al., 2014) but how exactly additional age effected susceptibility to DCS is not clear from this study. The first dive was made in the chamber with larger rats from other experiments but in the second dive the rats in this experiment unaccompanied in the chamber. Again, possibly stress confounded the difference, for example if pheromones were detected from other strains in the first experiment and this was somehow protective, (although there is nothing to suggest this possibility in the literature). Lastly, we cannot predict what effect the four rats who made only the first dive would have actually had if they had had the opportunity to make the second dive. We showed that, hypothetically, even if they had survived the second dive then age would have remained significant but we cannot know what their weights would have been at age 13 weeks and so this is tentative at best. 


\section{Conclusion}

Rat models appear to have the potential to contribute to mankind's understanding of the influence age exerts upon risk of DCS among divers. Even given the above limitations we are now confident enough of the existence of an association to proceed with modelling the effect size of age upon DCS outcome in rats in a much larger study.

\section{Declaration of Interests}

The research leading to this publication received funding from the People Programme (Marie Curie Actions) of the European Union's Seventh Framework Programme FRP/2007-2013/ under REA grant agreement $\mathrm{n}^{\circ} 264816$ PHYPODE. Ingrid Eftedal received funding from the Norwegian Research Council and Statoil ASA under Petromaks project $\mathrm{n}^{\circ} 220546$. 


\section{References}

ARDESTANI, S.B., BUZZACOTT, P. \& EFTEDAL, I. 2015. The aging diver : endothelial biochemistry and its potential implications for cardiovascular health. Diving Hyperb Med, 45, 235-9.

ARIELI, R., SVIDOVSKY, P. \& ABRAMOVICH, A. 2007. Decompression sickness in the rat following a dive on trimix: recompression therapy with oxygen vs. heliox and oxygen. J Appl Physiol, 102, 1324-8.

BOUSSUGES, A., RETALI, G., BODERE-MELIN, M., GARDETTE, B. \& CARTURAN, D. 2009. Gender differences in circulating bubble production after SCUBA diving. Clin Physiol Funct Imaging, 29, 400-405.

BUZZACOTT, P., LAMBRECHTS, K., MAZUR, A., WANG, Q., PAPADOPOULOU, V., THERON, M., BALESTRA, C. \& GUERRERO, F. 2014. A ternary model of decompression sickness in rats. Comput Biol Med, 55, 74-8.

CARTURAN, D., BOUSSUGES, A., BURNET, H., FONDARAI, J., VANUXEM, P. \& GARDETTE, B. 1999. Circulating venous bubbles in recreational diving: relationships with age, weight, maximal oxygen uptake and body fat percentage. Int. J. Sports Med., 20,410-14.

CARTURAN, D., BOUSSUGES, A., VANUXEM, P., BAR-HEN, A., BURNET, H. \& GARDETTE, B. 2002. Ascent rate, age, maximal oxygen uptake, adiposity, and circulating venous bubbles after diving. J. Appl. Physiol., 93, 1349-1356.

CSISZAR, A., UNGVARI, Z., EDWARDS, J. G., KAMINSKI, P., WOLIN, M. S., KOLLER, A. \& KALEY, G. 2002. Aging-induced phenotypic changes and oxidative stress impair coronary arteriolar function. Circ Res, 90, 1159-66. 
LAKATTA, E. G. 2003. Arterial and cardiac aging: major shareholders in cardiovascular disease enterprises: Part III: cellular and molecular clues to heart and arterial aging. Circulation, 107, 490-7.

LAMBRECHTS, K., PONTIER, J., BALESTRA, C., MAZUR, A., WANG, Q., BUZZACOTT, P., THERON, M., MANSOURATI, J. \& GUERRERO, F. 2013. Effect of a single, open sea, air scuba dive on human micro- and macrovascular function. Eur J Appl Physiol, 113, 2637-2645.

LILLO, R. S. 1988. Effect of N2-He-O2 on decompression outcome in rats after variable time-at-depth dives. J. Appl. Physiol., 64, 2042-52.

LILLO, R. S. \& MACCALLUM, M. E. 1991. Decompression comparison of N2 and O2 in rats. Undersea Biomed Res, 18, 317-31.

LILLO, R. S., HIMM, J.F., WEATHERSBY, P.K., TEMPLE, D.J., GAULT, K.A. \& DROMSKY, D.M. 2002. Using animal data to improve prediction of human decompression risk following air-saturation dives. J Appl Physiol, 93, 216-26.MAZUR, A., BUZZACOTT, P., LAMBRECHTS, K., WANG, Q., BELHOMME, M., THERON, M., POPOV, G., DISTEFANO, G. \& GUERRERO, F. 2014. Different effect of L-NAME treatment on susceptibility to decompression sickness in male and female rats. Appl Physiol Nutr Metab, $39,1280-5$.

MONTCALM-SMITH, E. A., MCCARRON, R. M., PORTER, W. R., LILLO, R. S., THOMAS, J. T. \& AUKER, C. R. 2010. Acclimation to decompression sickness in rats. J Appl Physiol, 108, 596-603.

SALLEE, T. \& ADAMS, G. M. 1970. Symptamology of decompression sickness in male Sprague-Dawley rats. Aerospace Med, 41, 1358-1361.

SENGUPTA, P. 2013. The laboratory rat: Its age with humans. Int J Prev Med, 4, 624-630. 
SULAIMAN, Z.M., PILMANIS, A.A. \& O'CONNOR, R.B. 1997. Relationship between age and susceptibility to altitude decompression sickness.. Aviat Space Environ Med, 68, 695-8.WANG, Q., GUERRERO, F., MAZUR, A., LAMBRECHTS, K., BUZZACOTT, P., BELHOMME, M. \& THERON, M. 2014. ROS, Mitochondria, and Endothelial Cell Death during In Vitro Simulated Dives. Med Sci Sports Exerc, 47, 1362-71. 
Table 1: Mean weight (SD) per batch by age

\begin{tabular}{lccccc}
\hline Batch & \multicolumn{3}{c}{1} & \multicolumn{2}{c}{2} \\
\hline Age & (weeks) & $11(\mathrm{n}=10)$ & $13(\mathrm{n}=8)$ & $11(\mathrm{n}=10)$ & $13(\mathrm{n}=8)$ \\
Weight & $(\mathrm{g})(\mathrm{SD})$ & $268(12)$ & $\mathbf{3 5 8}(11)$ & $\mathbf{3 3 6}(12)$ & $400(21)$ \\
\hline
\end{tabular}

\section{List of Figures}

Figure 1: Decompression health outcome by age and overall

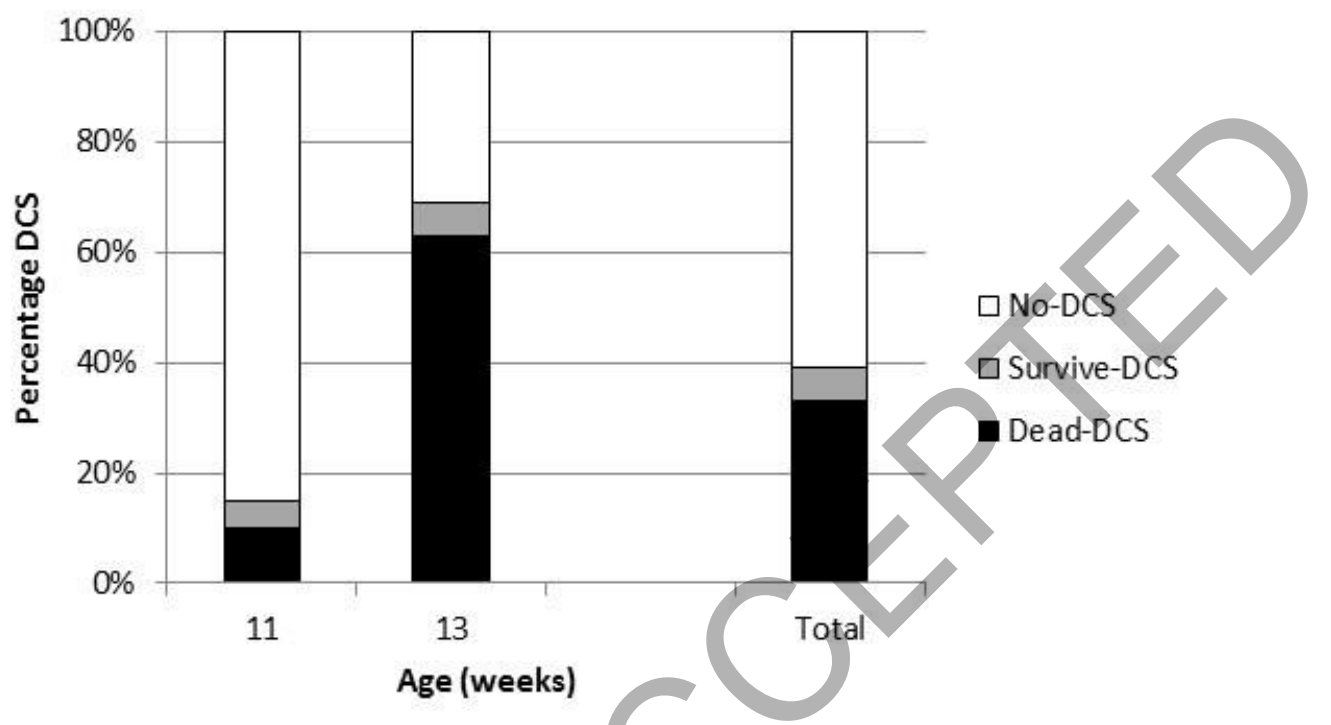

